\title{
Prevalence and Predictive Factors for Leg Ulcers in Sickle Cell Disease Patients in Saudi Arabia: A Cross-Sectional Observational Study
}

Feroze Kaliyadan ${ }^{1}$, Ahmed Z. Alkhars ${ }^{2}$, Alreem A. Albaqshi ${ }^{3}$, Hajar M. AlHajri ${ }^{3}$, Norah K. Albaqshi ${ }^{3}$, Rawan M. Aldihnayn ${ }^{3}$, Zainab Y. Almarzooq ${ }^{3}$

1. Dermatology, College of Medicine, King Faisal University, Al-Ahsa, SAU 2. General Medicine and Surgery, College of Medicine, King Faisal University, Al-Ahsa, SAU 3. Medicine, College of Medicine, King Faisal University, Al-Ahsa, SAU

Corresponding author: Ahmed Z. Alkhars, azamkx@gmail.com

\section{Abstract}

\section{Introduction}

Saudi Arabia has a high prevalence of sickle cell disease (SCD). Leg ulceration is one of the complications associated with SCD. There is a gap in the literature in regard to the prevalence of leg ulcers among SCD patients in Saudi Arabia.

\section{Objectives}

The primary objective of this study was to evaluate the lifetime prevalence of leg ulcers in SCD patients in our population and to study the predictive factors of leg ulcers by using sociodemographic factors, clinical manifestations of SCD, and other relevant factors like hydroxyurea.

\section{Methods}

A cross-sectional study design was utilized. Data collection was done using an electronic survey to collect self-reported information for the prevalence of leg ulcers and possible associated factors. The survey was distributed using social media platforms. Chi-square test was used to test for the presence of an association between having leg ulcers and sociodemographic variables as well as SCD related history. Furthermore, binary logistic regression was utilized to determine factors predicting the incidence of leg ulcers among SCD.

\section{Results}

A total of 790 valid responses were included in the study. Among these, 646 were included in the analysis of leg ulcers prevalence. From them, 52 (8\%) SCD patients reported a history of leg ulcers. The male to female ratio was $(9.7 \%$ vs $7.2 \%)$. The age group most affected by leg ulcers was those older than $50(16.7 \%)$. There was no significant association between a history of leg ulcers and sociodemographic variables. The only predictive factors for leg ulcers were having six to eight vaso-occlusive crises per month and having more than eight vaso-occlusive crises per month.

Review began 10/13/2020 Review ended 10/21/2020 Published 10/31/2020

\section{() Copyright 2020}

Kaliyadan et al. This is an open access article distributed under the terms of the Creative Commons Attribution License CC-BY 4.0., which permits unrestricted use, distribution, and reproduction in any medium, provided the original author and source are credited.

\section{Conclusion}

Leg ulcers among SCD patients in Saudi Arabia were considerably prevalent (8\%). There was no statistically significant correlation between leg ulceration and sociodemographic variables. Leg ulcers were more likely in patients with a history of highly frequent vaso-occlusive crises. No association was found between the incidence of leg ulcers and other complications of sickle cell disease or hydroxyurea.

Categories: Dermatology, Epidemiology/Public Health, Hematology

Keywords: sickle cell disease, prevalence, leg ulcers, saudi arabia

\section{Introduction}

Sickle cell disease (SCD) is an autosomal recessive hemoglobinopathy characterized by the formation of abnormal red blood cell (RBC) shape with defective hemoglobin called hemoglobin S (HbS) [1]. The genotype $(\mathrm{HbS})$ is caused by a mutation in the sixth amino acid of the beta-globin gene substituting a hydrophobic valine amino acid for glutamic acid. This change makes the HbS molecules more likely to polymerize in states of dehydration, hypoxia, or acidosis, affecting the RBCs shape to change from a normal biconcave disc shape to a sickle shape [2]. The change to a sickle shape results in anemia, and vaso-occlusion which in turn leads to SCD-associated clinical manifestations [3-5]. With time SCD can cause complications such as acute chest syndrome, priapism, pulmonary hypertension, cerebrovascular diseases, retinopathy, and skin ulcers $[5]$. 
Skin ulcers represent one of the most common and the most distressing cutaneous complication of SCD with a reported incidence that reach up to $25 \%-75 \%[6,7]$. Chronic and recurrent ulcers can significantly affect the quality of life of sickle cell patients. Ulceration occurs due to poor circulation and perfusion especially in areas that have thin skin and low subcutaneous fat, like the medial and lateral malleoli, anterior tibia, dorsum, and the area overlying the Achilles tendon [2]. The pathogenesis of leg ulcers in SCD is not fully understood. However, there are several complex interactions of factors that are thought to play a role in the pathophysiology. For example, trauma can cause sickle cell ulcers by stimulating the sickling of RBCs, which leads to obstruction of the vessels, ending up with ischemia and tissue necrosis. Also, the elevation of venous blood pressure resulting from venous insufficiency could contribute to the formation of sickle cell ulcers. Moreover, anemia may play a major role in hypoxia causing oxygen deficiency and tissue necrosis. As well as for thrombocytosis when it presents in a patient with SCD, it leads to increased blood viscosity, promoting thrombosis and vascular blockage [8].

SCD is the most common single-gene blood disorder worldwide accounting for $70 \%$ of total hemoglobinopathies [7]. Studies have reported that SCD is highly prevalent in Saudi Arabia with an estimation of $0.5 \%$ for sickle cell trait (SCT) and $0.038 \%$ for SCD through the screening done by the premarital program. Newborn screening estimated a prevalence of $21 \%$ for SCT and $2.6 \%$ for SCD [9].

Although SCD is endemic in Saudi Arabia and despite the recognition of leg ulcers as a commonly encountered complication in sickle cell patients, to the best of our knowledge, no previous studies have screened the prevalence of leg ulcers among sickle cell patients in Saudi Arabia. As there are no existing studies, it would be important to address this gap in the literature. In this study, we aim to determine the lifetime prevalence of leg ulcers in sickle cell patients in Saudi Arabia and its predictive factors.

\section{Materials And Methods \\ Study design and population}

A cross-sectional study targeting sickle cell patients living in Saudi Arabia to screen for the prevalence of leg ulcers among them. The study was conducted between August 2020 and October 2020.

\section{Study tool and its validation}

A survey was constructed and developed by the investigators and was presented to specialists in dermatology and medicine who revised it, improved it, and then approved it. The questionnaire was constructed in English and then translated to Arabic for it to be comprehensible for the targeted population. The Arabic version was first examined by three different language experts and the translation was approved after grammatic and linguistic modifications. After that, a pilot study was performed on a small group of people (15 persons) to confirm a uniform understanding of the questions.

\section{Data collection}

An online survey was created using Google forms for data collection. The online survey was disseminated to the community using social media platforms such as Twitter, Instagram, and WhatsApp. Volunteers were recruited for data collection from areas known to have a high prevalence of SCD in Saudi Arabia. Eight persons were recruited from the Eastern region, two from the Western region, five persons from the Southern region, and four persons from the Northern region. Although the questionnaire was disseminated to the general population, only sickle cell patients were invited to participate as they were the target. Data were obtained through an online self-administered questionnaire where participants first consent to participate in the study before starting to fill the questionnaire. The questionnaire included two sections, the first section has only one question which is if they had sickle cell disease or not. Only those who answered they had sickle cell disease were able to continue to the second section, those answering they were carrier and those answering they were free from the disease and trait were not allowed to proceed further. The second section contained four parts. The first part surveyed sociodemographic data including age, gender, nationality, level of education, and marital status. The second part asked about SCD related history including frequency of admission per year, frequency of vaso-occlusive crises per month, previous incidence of SCD complications (acute chest syndrome, priapism, and stroke), and usage of Hydroxyurea. The third part screened for the presence of other causes of leg ulcers including thalassemia, chronic venous insufficiency, and systemic lupus erythematosus. The fourth and the last part was about the dermatological aspects of SCD which surveyed the prevalence of leg ulcers, their frequency, were they painful or not and if they were associated with vaso-occlusive crises or not, the investigation that was conducted to be diagnosed with leg ulcers, the treatment plan for leg ulcers, and the duration of healing time.

\section{Sampling and sample size}

The used sampling technique was convenient random sampling where an online questionnaire was dispersed on social media platforms and sickle cell patients were invited to fill it up. The sample size was calculated using the formula $\mathrm{n}=\mathrm{z} 2 \mathrm{pq} \backslash \mathrm{d} 2$. With a confidence level of $95 \%$, an estimated proportion of $50 \%$, and a $5 \%$ level of precision. The minimum sample size was calculated to be 385 . However, more participants and candidates were included to ensure the sufficiency and accuracy of the results. Since it was an online 


\section{Inclusion and exclusion criteria}

Any patient with a previous diagnosis of sickle cell disease, consenting to participate in the study was included. Carriers of sickle cell trait and those free from trait and disease were excluded. Participants having sickle cell disease with any of the following diseases (thalassemia, chronic venous insufficiency, and systemic lupus erythematosus) were not included in the analysis for the part screening for leg ulcers and its associated history as they might be the cause of the ulceration and not sickle cell disease.

\section{Statistical analysis}

Data analysis was performed using Statistical Package for the Social Sciences (SPSS) version 23 (IBM Corp., Armonk, NY). Frequency and percentages were used to display categorical variables. Chi-square test was used to test for the presence of an association between having leg ulcers and sociodemographic variables as well as SCD-related history. Furthermore, binary logistic regression was utilized to determine predictive factors predicting the incidence of leg ulcers among SCD, the following variables were entered to the model (gender, age, being repetitively hospitalized due to SCD, frequency of hospitalization per year, frequency of vaso-occlusive per month, history of acute chest syndrome, history of priapism, history of stroke, utilization of hydroxyurea). Model fitness-of-good was tested using Omnibus test and Hosmer and Lemeshow test. The level of significance was set at 0.05 .

\section{Results}

A total of 3245 participated in the study, of which 790 had sickle cell disease, fitted the inclusion criteria, and therefore were included in the study. 505 were excluded for being carriers and 1935 were excluded as they were free from both the trait and the disease. Table 1 shows the sociodemographic profile of the participants having sickle cell disease. 261 (33\%) were males and 529 (67\%) were females. The age distribution of participants was as following 85 (10.8\%) were 18 years old and younger, 236 (29.9\%) were between 19 and 24 years, 132 (16.7\%) were between 25 and 30 years, 200 (25.3\%) were between 31 and 40 years, 107 (13.5\%) were between 41 and 50 years and 30 (3.8\%) were older than 50 years. 695 (88\%) were Saudi and 95 (12\%) were not Saudi. As for the place of residency, 693 (87.7\%) were from the Eastern Region, 37 (4.7\%) were from the Western Region, 33 (4.2\%) were from the Northern Region and 27 (3.4\%) were from the Southern Region. 383 (48.5\%) were single, 390 (49.4\%) were married and 17 (2.2\%) were divorced or widowed. 102 (12.9\%) had primary - intermediate school education, 225 (28.5\%) had high school education, 438 (55.4\%) had diploma / bachelor's degree and 25 (3.2\%) had master/Ph.D. degree. 


\title{
Cureus
}

Demographical Characteristics

Gender

Male

Female

Age

18 years and younger
$19-24$
$25-30$
$31-40$
$41-50$

Older than 50 years

Nationality

Saudi

Non-Saudi

Place of Residency

\begin{abstract}
Eastern Region
Western Region

Northern Region

Southern Region
\end{abstract}

Marital Status

Single

Married

Divorced / Widowed

Education

Primary - Intermediate School

High School

Diploma / Bachelor's degree

TABLE 1: Sociodemographic profile of the participants having sickle cell disease $(n=790)$

Table 2 shows the hospitalization and vaso-occlusive crisis history among sickle cell disease patients. When asked if the participants do repetitively get hospitalized due to SCD, 566 (71.6\%) answered yes. The average frequency of hospitalization due to SCD is as following 236 (29.9\%) answered 0 times, 358 (45.3\%) answered 1-2 times, 114 (14.4\%) answered 3-5 times, 40 (5.1\%) answered 6-8 times and 42 (5.3\%) answered more than 8 times. The average frequency of painful vaso-occlusive crisis due to SCD is as following 227 (28.7\%) answered 0 times, 405 (51.3\%) answered 1-2 times, 98 (12.4\%) answered 3-5 times, 37 (4.7\%) answered 6-8 times and $23(2.9 \%)$ answered more than 8 times. 


\section{Cureus}

\section{Question}

Q1/ Do you get repetitively hospitalized due to SCD?

Yes

No

Q2/ On average how frequently do you get hospitalized per year?

0

1 - 2 times

3 - 5 times

6 - 8 times

More than 8 times

Q3/ On average how frequently do you get pain crises per month?

0

$1-2$ times

$3-5$ times

$6-8$ times

More than 8 times $\mathbf{n}$

$\%$

566

71.6

224

28.4

236

29.9

358

45.3

14.4

114

5.1

42

5.3

227

28.70

405

51.30

98

12.40

37

4.70

23

2.9

TABLE 2: Hospitalization and vaso-occlusive crisis among sickle cell disease $(n=790)$

Figure 1 illustrates the prevalence of sickle cell disease complications among diseased patients. 269 (34.1\%) have previously suffered from acute chest syndrome, 34 (4.3\%) have previously suffered from priapism, 15 (1.9\%) have previously suffered from a stroke, whilst 485 (61.4\%) have never suffered from any of the mentioned complications.

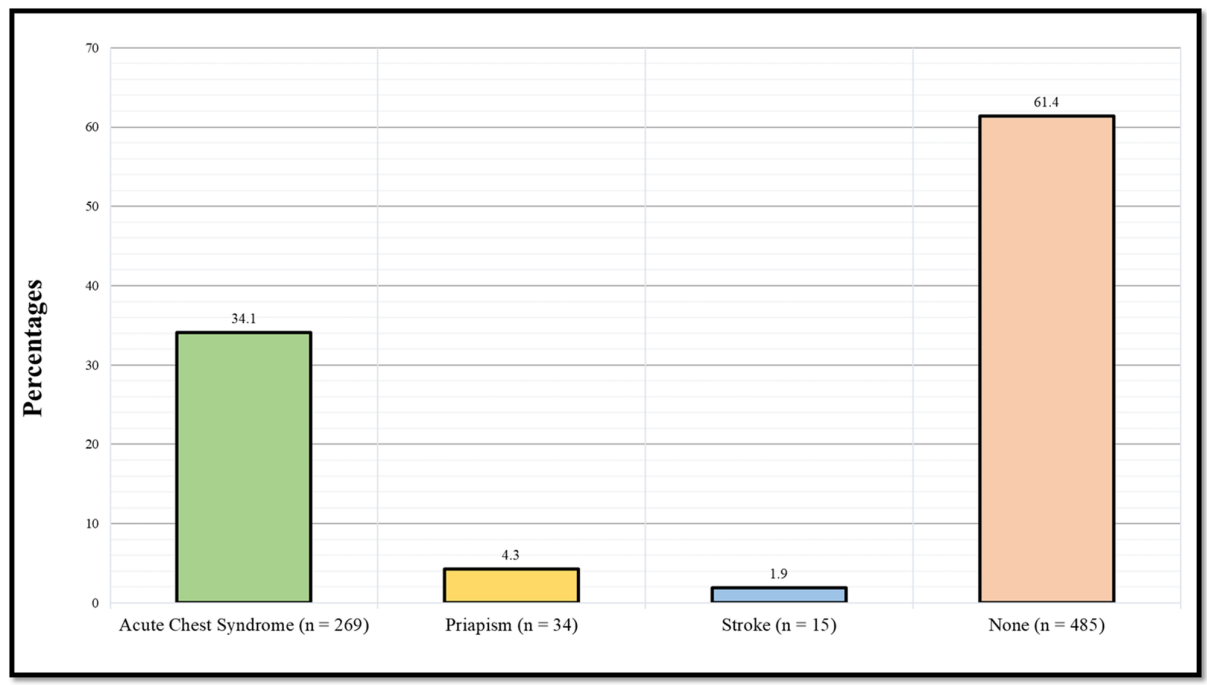

FIGURE 1: Prevalence of sickle cell disease complications among sickle cell disease patients

Figure 2 illustrates the utilization level of hydroxyurea among sickle cell patients. 269 (34.1\%) uses hydroxyurea, whilst 521 (65.9\%) don't. 


\section{Cureus}

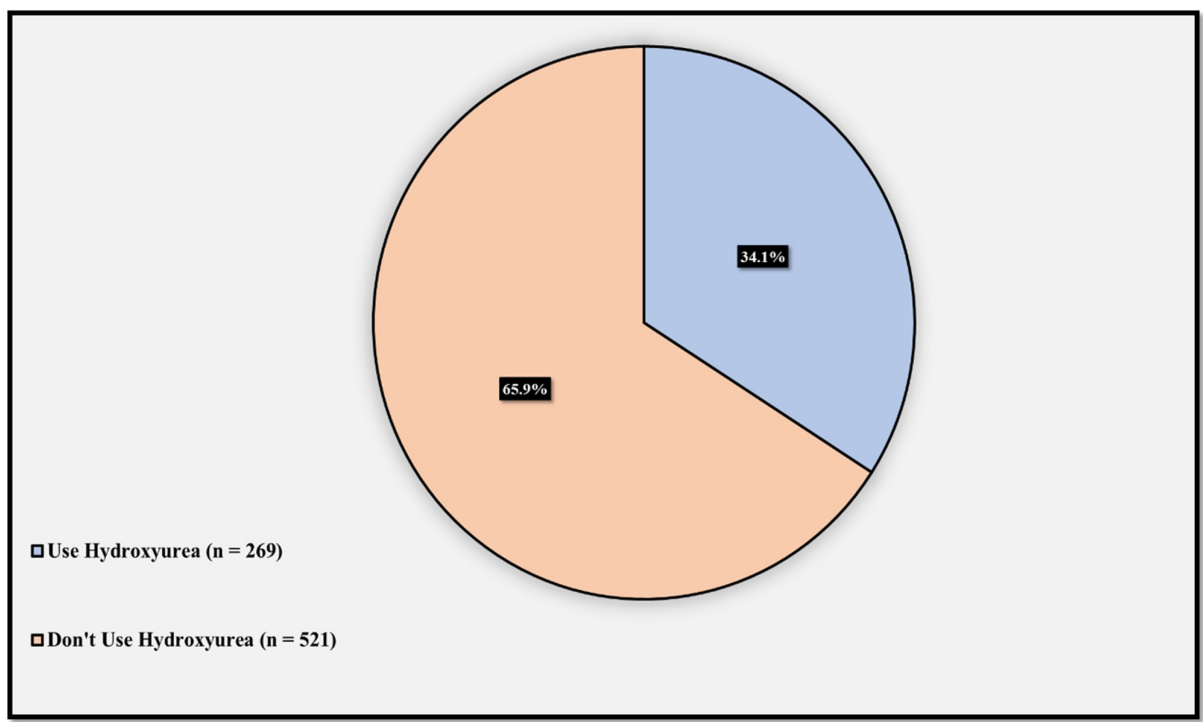

FIGURE 2: Utilization of hydroxyurea among sickle cell disease patients

Figure 3 demonstrates the prevalence of diseases that can cause leg ulcers among sickle cell disease patients other than sickle cell disease (thalassemia, chronic venous insufficiency, and systemic lupus erythematosus). 98 (12.4\%) had thalassemia, 36 (4.6\%) had chronic venous insufficiency, 14 (1.8\%) had systemic lupus erythematosus, whilst 646 (81.8\%) did not have any of the mentioned diseases. Those having any disease that can cause leg ulcers were excluded from further analysis (analysis of leg ulcer prevalence and associated history).

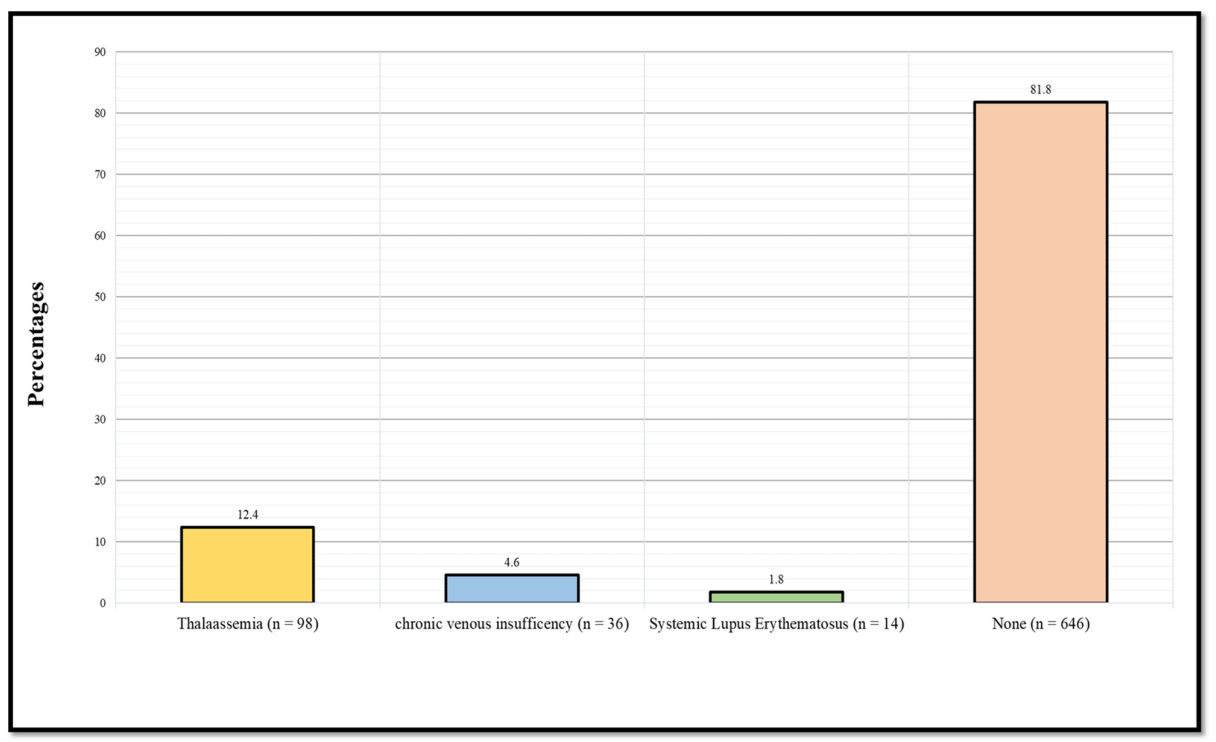

FIGURE 3: Prevalence of other diseases that can cause leg ulcers among sickle cell disease patients

Figure 4 demonstrates the lifetime prevalence of leg ulcers among sickle cell disease patients with no secondary causes of leg ulcers. 52 (8\%) had leg ulcers, whilst 594 (92\%) do not. 


\section{Cureus}

口Have / Had Leg Ulcer Before $(\mathbf{n}=\mathbf{5 2})$

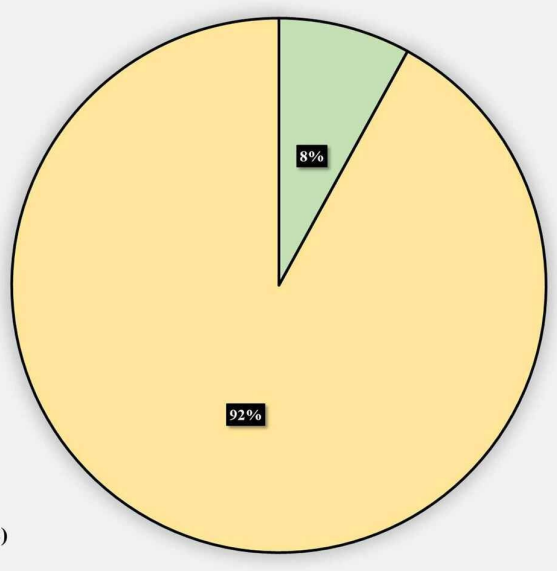

口Never had Leg Ulcers $(n=594)$

FIGURE 4: Lifetime prevalence of leg ulcers among sickle cell disease patients

Table 3 displays the leg ulcer related history in SCD patients affected with leg ulcers. 33 (63.5\%) suffered from leg ulcers 1-2 times. 8 (15.4\%) suffered from leg ulcers 3-4 times and 11 (21.2\%) suffered from leg ulcers more than 4 times. 35 (67.3\%) stated the ulcer was painful and 17 (32.7\%) stated it was not. Only 17 (32.7\%) stated that there was an association between the incidence of leg ulcers and vaso-occlusive crisis. When asked which investigation was conducted in order to diagnose the leg ulcer, $6(11.5 \%)$ said a biopsy was performed to be diagnosed, 5 (9.6\%) said they did an ultrasound imaging to be diagnosed, whilst 41 (78.8\%) were diagnosed clinically without investigation. When asked how the leg ulcer was treated, $11(21.2 \%)$ reported analgesics as the mainstay of treatment, 37 (71.2\%) reported topical treatment (creams and ointment) as the primary form of treatment, 3 (5.8\%) reported having blood transfusion for the treatment of ulcer and 1 (1.9\%) reported only dressing as the mainstay of treatment. As for the reported healing time, 10 (19.2\%) said it was few days, 15 (28.8\%) said it was one week, 6 (11.5\%) said it was two to three weeks, 6 $(11.5 \%)$ said it was one month, $6(11.5 \%)$ said it was two to three months and $9(17.3 \%)$ said it was more than three months. 


\section{Cureus}

Question

Q1/ How many times have you suffered from leg ulcers?

1 - 2 times

3- 4 times

More than 4 times

Q2/ Was the ulcer painful?

Yes

No

Q3/ Was the ulcer associated with VOC?

Yes

No

Q4/ Which of the following have been conducted to diagnose you with leg ulcers? (more than one answer can be chosen)

Biopsy

$$
6
$$

Ultrasound

5

Clinical Examination

Q5/ How was the ulcer treated?

Analgesics

Topical Treatment (Creams and ointments)

Blood Transfusion

Dressing

Q6/ How long did the ulcer take to heal?

Few days

1 week

2 - 3 weeks

TABLE 3: Leg ulcers history among sickle cell disease patients with leg ulcers $(n=52)$

Table 4 displays the factors associated with the incidence of leg ulcers in patients with sickle cell disease. None of the sociodemographic variables were associated with the incidence of leg ulcers in sickle cell disease. As for the association between sickle cell disease-related history, only the average frequency of painful vaso-occlusive crisis was significantly associated with the incidence of leg ulcers $\left(p<0.001^{*}\right)$. Using hydroxyurea was near significant $(\mathrm{p}=0.056)$

Demographical Characteristics

.

Yes

Have you ever suffered from leg ulcers?

Gender

$\begin{array}{lcr}\text { Male } & 21(9.7 \%) & 195(90.3 \%) \\ \text { Female } & 31(7.2 \%) & 399(92.8 \%)\end{array}$

Yes No

\section{P-value}

$399(92.8 \%)$ 


\section{Cureus}

Age

$\begin{array}{lll}18 \text { years and younger } & 5(7.2 \%) & 64(92.8 \%) \\ 19-24 & 10(5.1 \%) & 186(94.9 \%) \\ 25-30 & 11(10.2 \%) & 97(89.8 \%) \\ 31-40 & 13(7.9 \%) & 151(92.1 \%) \\ 41-50 & 9(10.6 \%) & 76(89.4 \%) \\ \text { Older than } 50 \text { years } & 4(16.7 \%) & 20(83.3 \%)\end{array}$

Nationality
Saudi

Non-Saudi

47 (8.2\%)

$5(6.7 \%)$

$47(8.1 \%)$

$3(10.3 \%)$

$1(4.2 \%)$

$1(6.3 \%)$

Southern Region

Marital Status

Single

Married

Divorced / Widowed

Education

Primary - Intermediate School

High School

Master / Ph.D. Degree

Do you get repetitively hospitalized due to SCD?

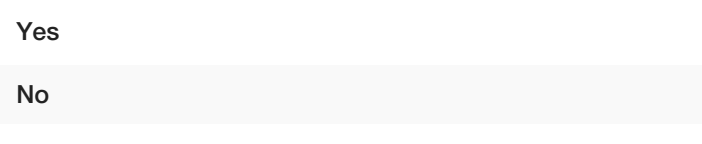

On average how frequently do you get hospitalized per year?

0

1 - 2 times

3 - 5 times

6 - 8 times

More than 8 times

On average how frequently do you get pain crises per month?

$1-2$ times
$3-5$ times
$6-8$ times

More than 8 times

$8(4.1 \%)$

$28(8.4 \%)$

$4(5.3 \%)$

$8(28.6 \%)$

$4(36.4 \%)$
Diploma / bachelor's degree
$524(91.8 \%)$

$70(93.3 \%)$

$530(91.9 \%)$

$26(89.7 \%)$

$23(95.8 \%)$

$15(93.8 \%)$

$294(92.2 \%)$

$286(91.4 \%)$

$14(100 \%)$

$72(92.3 \%)$

$172(90.5 \%)$

$333(92.8 \%)$

$17(89.5 \%)$

$10(91 \%)$

$170(94.4 \%)$

$196(96.1 \%)$

$263(90.7 \%)$

$78(87.6 \%)$

$29(87.9 \%)$

28 (93.3\%)

0.079

$188(95.9 \%)$

$307(91.6 \%)$

72 (94.7\%)

$20(71.4 \%)$

$7(63.6 \%)$

0.640

0.856

0.799
0.500

0.289

Have you ever suffered from acute chest syndrome? 


\section{Cureus}

Yes

No

Have you ever suffered from priapism?

Yes

No

Have you ever suffered from a stroke?

Yes

No

Do you use hydroxyurea?
$20(9.5 \%)$

$32(7.3 \%)$

$48(7.7 \%)$

$1(12.5 \%)$

$51(8 \%)$

$7(87.5 \%)$

0.642

$587(92 \%)$

$186(89 \%)$

0.056

$23(11 \%)$

No

408 (93.4\%)

TABLE 4: Factors associated with the incidence of leg ulcers in patients with sickle cell disease $(n=646)$

*Significant at level 0.05

Table 5 displays the multivariate logistic regression for the prediction of leg ulcer incidence among sickle cell disease patients. The predictability of incidence of leg ulcers among SCD patients was tested using the following variables: gender, age, frequency of hospitalization per year, frequency of vaso-occlusive per month, history of acute chest syndrome, history of priapism, history of stroke, utilization of hydroxyurea was tested. The presence of the following characteristics was significantly more predisposing to leg ulcers: having painful vaso-occlusive crises 6-8 times per month or more than 8 times. 


\section{Cureus}

\section{Variables}

\section{Demographics}

P-Value Odds Ratio Confidence Interval

Gender (Male vs Female)

0.92

Age (18 Years and younger is the Referent)

$$
\begin{aligned}
& 19-24 \\
& 25-30 \\
& 31-40 \\
& 41-50
\end{aligned}
$$

$0.53-2.023$

Older than 50 years

Sickle Cell Disease History

\begin{tabular}{llll}
0.456 & 0.642 & 0.201 & 2.057 \\
0.589 & 1.376 & 0.433 & 4.376 \\
0.755 & 1.196 & 0.389 & 3.676 \\
0.59 & 1.4 & 0.412 & 4.754 \\
0.153 & 2.96 & 0.667 & 13.129 \\
P-Value & Odds Ratio & \multicolumn{2}{l}{ Confidence Interval }
\end{tabular}

On average how frequently do you get hospitalized per year? ( 0 is the Referent)

$1-2$ times
$3-5$ times
$6-8$ times

0.149

More than 8 times

On average how frequently do you get pain crises per month? ( 0 is the Referent)
1 - 2 times
3 - 5 times
6 - 8 times

More than 8 times

Have you ever suffered from acute chest syndrome? (Yes vs No)

Have you ever suffered from priapism? (Yes vs No)

Have you ever suffered from a stroke? (Yes vs No)

Do you use hydroxyurea? (Yes vs No)
0.161

0.911

1.839

0.928

$0.001^{*}$

8.206

$0.001^{*}$

19.218

0.719

0.889

0.365

0.551

0.844

1.291

$0.352 \quad 0.737$
0.785

4.31

$0.25 \quad 3.444$

$2.499 \quad 26.952$

$3.321 \quad 111.226$

$0.469 \quad 1.686$

$0.152 \quad 2.001$

$0.102 \quad 16.419$

$0.388 \quad 1.401$

\section{TABLE 5: Multivariate logistic regression (factors predicting incidence leg ulcers)}

\section{Discussion}

In this study, the lifetime prevalence of leg ulcers among SCD patients in Saudi Arabia was 8\%. To the best of our knowledge, no previous studies have described the prevalence of leg ulcers in Saudi Arabia. However, other studies reported that the prevalence of leg ulcers among SCD patients in other countries varied and ranged from low to high. Previous studies revealed that leg ulceration among sickle cell patients prevalence was $2.5 \%$ in the United States [10], 3.5\% in Italy, [11] 5.9\% in Nigeria [12], 10.6\% in Ghana [13], 13.2\% in Sierra Leone [13], $29.5 \%$ in Jamaica [14], and up to $43 \%$ in Brazil [15]. These observations further confirm the presence of a geographical variation with respect to clinical features of SCD, recognized by Nolan et al., Trent et al. and Ballas [8,16,17]. SCD genotype has been suggested by Minniti et al. as an explanation of this geographical variation, where patients within countries having specific SS genotype prevalence are more likely to be affected [18]. We too agree that the prevalence of specific genotypes according to the geographical region might have a bearing on leg ulcers, as with other phenotypic association with different genotypes of SCD. Another factor to put into consideration is the method of data collection, each study had its own way of data collection which might have contributed to some degree to this varying level of leg ulcer prevalence.

In this study, although the prevalence of leg ulcers was higher in males, the gender variation was not statistically significant. This is in contrast with other studies where males were significantly more affected 
than females [10,12]. However, it is consistent with the finding of Halabi-Tawil et al. and Morgan [19,20]. Halabi-Tawil et al. mentioned in their study that this male predominance of leg ulcer prevalence is noted in studies conducted in North America but not in studies conducted in African countries and Jamaica. This makes the gender pattern seen in Saudi Arabia similar to the one seen in Africa and Jamaica.

Cumming et al. and Antwi-Boasiako stated in their study that SCD patients older than 18 were found to be at more risk for leg ulcers compared to younger patients. Thus, they suggest a correlation between age and leg ulcers $[11,14]$. These findings are not consistent with our study in which there was no significant difference in leg ulcer prevalence between different age groups, although a relative increase of prevalence was seen in older age groups.

In this study, we found no association between socioeconomic status (represented by income) and the prevalence of leg ulcers. This is in contrast with the findings of Minniti and Kato [21], Cumming et al. [14], and Olatunya et al. [12], where an association has been found between leg ulcers and socioeconomic status. Poor socioeconomic status has been identified as a risk factor for leg ulcers in their work; they explain this association through the assumption that people with low socioeconomic status have generally lack of care and poor nutritional intake. It is possible that the relatively high socio-economic status of the country in general and the subsidized health care system could be partly responsible for this finding in our study.

A significant association between painful vaso-occlusive crisis and prevalence of leg ulcers was observed in this study, where it has been found that a high rate of vaso-occlusive crisis per month is an independent risk factor for leg ulcers (particularly in those with six to eight times a month and more than 8 times a month). This finding opposes the findings of previous studies where an inverse relationship was found between vasoocclusive crisis and leg ulcers according to Antwi-Boasiako et al, Olatunya et al, and Madu et al. [11,12,22]. They observed a significant decrease in the incidence of vaso-occlusive crisis in patients with leg ulcers. Antwi-Boasiako et al. explained this phenomenon by suggesting that vaso-occlusive crises in sickle cell disease are more commonly associated with a different phenotype as compared to leg ulcers and that vasoocclusive crisis are related to viscosity while leg ulcers are related to hemolysis. This is one aspect that needs to be studied more and large genetic association studies would probably help to unravel the correlation between genotypes and phenotypes -in the context of specific clinical symptoms in SCD patients.

In our study, although those with SCD complications such as acute chest syndrome, stroke, and priapism had a relatively higher rate of leg ulcers, no significant correlation between leg ulcers and incidence of complications was present. However, previous studies have found a strong correlation between priapism, acute chest syndrome, and stroke with leg ulcers [23-25].

A relatively higher rate of leg ulcer incidence was observed in people using hydroxyurea, but this was not statistically significant. This is similar to the finding of Prabhash and Bapsy as well as the finding of Hwang et al., where they found that using hydroxyurea is associated with the incidence of leg ulcers, however, it is questionable whether using hydroxyurea in itself is contributing to the development of leg ulcers or if this association has another explanation as the association does not necessarily mean causation [26,27].

\section{Limitations}

The study has a self-reported cross-sectional design, which might subject the accuracy of the obtained data into question. Also, neither physical examination nor laboratory investigations were obtained and analyzed to confirm the diagnosis and determine the biomarkers highly associated with leg ulcers.

However, this study provides a good baseline about the prevalence of leg ulcers and we would recommend performing larger hospital-based studies where proper history taking, physical examination, and lab investigations are performed to identify the findings correlated with leg ulceration in SCD patients.

\section{Conclusions}

Leg ulcers among SCD patients in Saudi Arabia were considerably prevalent (8\%). There was no statistically significant correlation between leg ulceration and sociodemographic variables. Leg ulcers were more likely in patients with a history of highly frequent vaso-occlusive crises. No association was found between the incidence of leg ulcers and other complications of sickle cell disease or hydroxyurea.

\section{Additional Information \\ Disclosures}

Human subjects: Consent was obtained by all participants in this study. King Fahad Medical City issued approval FWA00018774. Animal subjects: All authors have confirmed that this study did not involve animal subjects or tissue. Conflicts of interest: In compliance with the ICMJE uniform disclosure form, all authors declare the following: Payment/services info: All authors have declared that no financial support was received from any organization for the submitted work. Financial relationships: All authors have declared that they have no financial relationships at present or within the previous three years with any 
organizations that might have an interest in the submitted work. Other relationships: All authors have declared that there are no other relationships or activities that could appear to have influenced the submitted work.

\section{Acknowledgements}

We would like to express our sincere gratitude to the data collectors who were generous in giving from their time and effort for the accomplishment and success of this research.

\section{References}

1. Ladizinski B, Bazakas A, Mistry N, Alavi A, Sibbald R, Salcido R: Sickle cell disease and leg ulcers . Adv Skin Wound Care. 2012, 25:420-428. 10.1097/01.ASW.0000419408.37323.0c

2. Jones H, Blinder M, Anadkat M: Cutaneous manifestations of sickle cell disease . Open J Blood Dis. 2013, 3:94-99. 10.4236/ojbd.2013.33019

3. Zaini RG: Sickle-cell anemia and Consanguinity among the Saudi Arabian population. Arch Med. 2016, 8:3.

4. Alkot M, Almaghrabi W, Najdi N, Otaibi M, Shatla M, Abdelbaki H: Prevalence of complications of sickle cell disease at Makkah Al-Mukaramah, Saudi Arabia. Ann Clin Lab Res. 2018, 6:226. 10.21767/23865180.1000226

5. Meier E: Treatment options for sickle cell disease . Pediatr Clin North Am. 2018, 65:427-443. 10.1016/j.pcl.2018.01.005

6. Soutou B, Senet P, Lionnet F, Habibi A, Aractingi S: Sickle cell disease induces resistance to cutaneous carcinogenesis. Orphanet J Rare Dis. 2020, 15:66. 10.1186/s13023-020-1341-9

7. Alavi A, Kirsner R: Hemoglobinopathies and leg ulcers. Int J Lower Extremity Wounds. 2015, 14:213-216. $10.1177 / 1534734615600069$

8. Trent J, Kirsner R: Leg ulcers in sickle cell disease . Adv Skin Wound Care. 2004, 17:410-416. 10.1097/00129334-200410000-00010

9. Hazzazi A, Ageeli M, Alfaqih A, Jaafari A, Malhan H, Bakkar M: Epidemiology and characteristics of sickle cell patients admitted to hospitals in Jazan region, Saudi Arabia. J Appl Hematol. 2020, 11:10-14. 10.4103/joah.joah 6719

10. Koshy M, Entsuah R, Koranda A, et al.: Leg ulcers in patients with sickle cell disease . Blood. 1989, 74:14031408.

11. Antwi-Boasiako C, Andemariam B, Colombatti R, et al.: A study of the geographic distribution and associated risk factors of leg ulcers within an international cohort of sickle cell disease patients: the CASiRe group analysis. Ann Hematol. 2020, 99:2073-2079. 10.1007/s00277-020-04057-8

12. Olatunya OS, Albuquerque DM, Adekile AD, Costa FF: Evaluation of sociodemographic, clinical, and laboratory markers of sickle leg ulcers among young nigerians at a tertiary health institution. Niger J Clin Pract. 2018, 21:882-887. 10.4103/njcp.njcp_4_18

13. Knox-Macaulay HH: Sickle cell disease in Sierra Leone: a clinical and haematological analysis in older children and adults. Ann Trop Med Parasitol. 1983, 77:411-419. 10.1080/00034983.1983.11811730

14. Cumming V, King L, Fraser R, Serjeant G, Reid M: Venous incompetence, poverty and lactate dehydrogenase in Jamaica are important predictors of leg ulceration in sickle cell anaemia. Br J Haematol. 2008, 142:119125. 10.1111/j.1365-2141.2008.07115.x

15. Figueiredo MS, Kerbauy J, Goncalves MS, et al.: Effect of alphathalassemia and beta-globin gene cluster haplotypes on the hematological and clinical features of sickle-cell anemia in Brazil. Am J Hematol. 1996, 53:72-76. 10.1002/(SICI)1096-8652(199610)53:2<72::AID-AJH3>3.0.CO;2-0

16. Nolan V, Adewoye A, Baldwin C, et al.: Sickle cell leg ulcers: associations with haemolysis and SNPs in Klotho, TEK and genes of the TGF-beta/BMP pathway. Br J Haematol. 2006, 133:570-578. 10.1111/j.13652141.2006.06074.x

17. Ballas SK: Sickle cell anemia: progress in pathogenesis and treatment . Drugs. 2002, 62:1143-1172 10.2165/00003495-200262080-00003

18. Minniti C, Eckman J, Sebastiani P, Steinberg M, Ballas S: Leg ulcers in sickle cell disease. Am J Hematol. 2010, 85:831-833. 10.1002/ajh.21838

19. Halabi-Tawil M, Lionnet F, Girot R, Bachmeyer C, Lévy P, Aractingi S: Sickle cell leg ulcers: a frequently disabling complication and a marker of severity. Br J Dermatol. 2007, 158:339-344. 10.1111/j.1365 2133.2007.08323.x

20. Morgan AG: Sickle cell leg ulcers. Int J Dermatol. 1985, 24:643-644. 10.1111/j.1365-4362.1985.tb05715.x

21. Minniti CP, Kato GJ: Critical reviews: how we treat sickle cell patients with leg ulcers . Am J Hematol. 2016, 91:22-30. 10.1002/aih.24134

22. Madu AJ, Ubesie A, Madu KA, Okwor B, Anigbo C: Evaluation of clinical and laboratory correlates of sickle leg ulcers. Wound Repair Regen. 2013, 21:808-812. 10.1111/wrr.12100

23. Belini Junior E, Silva DG, Torres Lde S, et al.: Severity of Brazilian sickle cell disease patients: severity scores and feasibility of the Bayesian network model use. Blood Cells Mol Dis. 2015, 54:321-327. 10.1016/j.bcmd.2015.01.011

24. Serjeant GR, Serjeant BE, Mohan JS, Clare A: Leg ulceration in sickle cell disease: medieval medicine in a modern world. Hematol Oncol Clin North Am. 2005, 19:943-956. 10.1016/j.hoc.2005.08.005

25. Kato GJ, McGowan V, Machado RF, et al.: Lactate dehydrogenase as a biomarker of hemolysis-associated nitric oxide resistance, priapism, leg ulceration, pulmonary hypertension, and death in patients with sickle cell disease. Blood. 2006, 107:2279-2285. 10.1182/blood-2005-06-2373

26. Prabhash K, Bapsy P: Hydroxyurea induced non-healing leg ulcer. Indian J Dermatol Venereol Leprol. 2005 , 71:50-52. http://www.bioline.org.br/request?dv05016

27. Hwang S, Hong S, Kim S, Seo J, Lee D, Sung H: A hydroxyurea-induced leg ulcer. Ann Dermatol. 2009, 21:39-41. 10.5021/ad.2009.21.1.39 